\title{
Desenvolvimento Institucional em Organizações da Sociedade Civil: Gestão Social ou Gestão Estratégica do Social?
}

\author{
Persson, Erik; Moretto Neto, Luís \\ Desenvolvimento Institucional em Organizações da Sociedade Civil: Gestão Social ou Gestão Estratégica do \\ Social? \\ Administração Pública e Gestão Social, vol. 12, núm. 3, 2020 \\ Universidade Federal de Viçosa, Brasil \\ Disponible en: http://www.redalyc.org/articulo.oa?id=351563312001
}

Esta obra está bajo una Licencia Creative Commons Atribución-NoComercial-SinDerivar 3.0 Internacional. 


\title{
Desenvolvimento Institucional em Organizações da Sociedade Civil: Gestão Social ou Gestão Estratégica do Social?
}

\begin{abstract}
Institutional Development in Civil Society Organizations: Social Management or Strategic Social Management? Desarrollo Institucional en Organizaciones de la Sociedad Civil: ¿Gestión Social o Gestión Estratégica de lo Social?
\end{abstract}

Erik Persson

King's College London (KCL), Reino Unido

Redalyc: http://www.redalyc.org/articulo.oa?

erik.ps@ufsc.br

Luis Moretto Neto

Universidade Federal de Santa Maria-UFSM, Brasil

luis.moretto.neto@ufsc.br

Recepción: 19 Marzo 2017

Aprobación: 09 Enero 2019

Publicación: 01 Julio 2020

\section{Resumo:}

Nos últimos anos, no Brasil, tem surgido no campo das Organizações da Sociedade Civil (OSCs) uma perspectiva teórica e prática denominada Desenvolvimento Institucional (DI). Para além de mero aprimoramento técnico-gerencial das organizações, o DI leva em conta seus posicionamentos no ambiente e suas intervenções para desempenhar suas funções de forma eficiente, legítima e sustentável. Neste diapasão, o propósito deste artigo é discutir se a proposta de DI em OSCs vai ao encontro dos pressupostos teóricos e conceituais da gestão social, tendo como fim imanente a emancipação dos sujeitos nessas organizações, ou se permanece arraigada nas premissas managerialistas dominantes da gestão estratégica. Argumentamos que, a despeito das ações de DI terem o potencial de promover espaços promissores para práticas comunicativas, reflexivas e emancipadoras de uma gestão social, esta nova corrente se aproxima, teórica e conceitualmente, de uma perspectiva de gestão estratégica do social, pendendo para a ortodoxia do gerencialismo.

Palavras-chave: Desenvolvimento Institucional, Terceiro Setor, Gestão Social, Managerialismo.

\section{ABstraCt:}

In recent years, a theoretical and practical perspective called Institutional Development (ID) has emerged in the field of Civil Society Organizations (CSOs) in Brazil. In addition to a merely technical and managerial improvement of organizations, the ID takes into account their positioning in the environment as well as their interventions to perform their functions in a relevant, justified and sustainable way. In this sense, the purpose of this article is to discuss whether the ID's proposal is in alignment with theoretical and conceptual assumptions of social management, whose the inherent purpose is the individuals' emancipation in organizations, or if it remains rested on the managerial dominant premises of strategic management. We argue that despite ID's actions have the potential to promote promising sites for communicative, reflexive and emancipatory practices, such a new theoretical-practical current is more closely affiliated to the strategic management perspective, tending toward the managerial orthodoxy.

KEYWORDS: Institutional Development, Third Sector, Social Management, Managerialism.

\section{Resumen:}

En los últimos años ha surgido en el campo de las Organizaciones de la Sociedad Civil (OSCs) en Brasil una perspectiva teórica y práctica denominada Desarrollo Institucional (DI). Además de mera mejora técnica y de gestión de las organizaciones, el DI considera sus posicionamientos en el entorno y las intervenciones para desempeñar de forma pertinente, legítima e sostenible sus funciones. En este sentido, el propósito de este ensayo es discutir si la propuesta de DI en OSCs cumple con las condiciones para una gestión social, cuyo fin inmanente es la emancipación de los individuos en las organizaciones, o si permanece arraigada en las premisas managerialistas dominantes de la gestión estratégica. Nosotros sostenemos que, aunque las acciones DI potencialmente confieren espacios promisorios para las prácticas comunicativas, reflexivas y emancipadoras de una gestión social, esta nueva corriente teórico-práctica se aproxima, teórica e conceptualmente, de una gestión estratégica do social y no de una gestión social, aproximándose de la ortodoxia del gerencialismo. 
Palabras Clave: Desarrollo Institucional, Tercer Sector, Gestión Social, Managerialismo.

\section{INTRODUÇÃo}

Há um discurso muito comum no que tange ao domínio da gestão em Organizações da Sociedade Civil (OSCs) ou terceiro setor, discurso que, em geral, envolve o argumento de que, num contexto de formação setorizada, fragmentada e focada na atividade social, as práticas gerenciais nas OSCs por muito tempo foram desconsideradas pelos profissionais do setor no Brasil, o que revelaria certa dicotomia entre o social e o administrativo, cuja fragilidade acarretou a herança histórica de organizações que não se sustentam, sobrevivendo na dependência do Estado (Salvatore, 2003). Apesar de avanços mais recentes, historicamente as organizações do terceiro setor caracterizam-se por limitações gerenciais no desempenho cotidiano dos papéis a que se propõem (Lewis, 2006), o que implica para muitas delas na incapacidade de garantirem sua sustentabilidade.

Segundo Falconer (1999, p. 8), "Notadamente, ressalta-se a fragilidade organizacional; a dependência de recursos financeiros governamentais e de agências internacionais, cada vez mais escassos; a falta de recursos humanos adequadamente capacitados e; a existência de obstáculos diversos para um melhor relacionamento com o Estado".

Decerto, durante muito tempo a finalidade das OSCs foi inicialmente voltada apenas ao atendimento das necessidades dos seus públicos, sendo as questões administrativas entendidas meramente como exigências formais (Salvatore, 2003) e, desse modo, secundárias, na medida em que muitas dessas organizações eram relativamente pequenas, com um padrão de gestão artesanal, simples e informal baseado em relações de confiança (Armani, 2013; Pereira, Moraes, Mattos, \& Palmisano, 2013). Segundo Lewis (2006), essas configurações, somadas a uma "cultura voltada à ação", contribuíram para o estabelecimento de uma série de desafios gerenciais no campo, como a dificuldade de monitorar o desempenho organizacional, os problemas na gestão de uma accountability múltipla, a demanda por estruturas gerenciais para equilibrar uma variedade de stakeholders, os conflitos entre voluntarismo e profissionalismo, a necessidade de manter os valores e a visão original das organizações e a tendência à definição de objetivos organizacionais vagos.

No Brasil, a partir da Constituição de 1988 em particular, a sociedade desperta para os fracassos institucionais dos aparelhos estatais e passa a buscar soluções coletivas para a crise social, particularmente por intermédio do terceiro setor (Tenório, 2006). Nesse contexto, as OSCs se veem conduzidas a ampararse cada vez mais em conhecimentos sobre gestão e em ações estratégicas (Soares \& Melo, 2010), tanto por conta das políticas de redução e reorientação do papel do Estado a partir das reformas administrativas gerenciais de orientação neoliberal (Bresser-Pereira, 2000; Fleury, 1997) e o decorrente escasseamento das fontes de financiamento estatal (Abdala, Assis, Gonçalves, \& Abdala, 2015), quanto pela maior exigência da sociedade brasileira por transparência e responsabilidade dessas organizações no que diz respeito à aplicação dos recursos captados e aos resultados alcançados (Rodrigues, 2003; Nanus, 2000).

Nessa perspectiva, para sua própria sobrevivência, as OSCs são levadas a buscar parcerias com a comunidade empresarial (Cunha \& Matias-Pereira, 2012) e a apropriar-se do pensamento, funções e instrumentos gerenciais aplicados no mercado e nos aparelhos estatais (Dar, 2007; Lewis, 2006). No entanto, conforme explica Armani (2013), ao invés de financiarem a operacionalização da organização como um todo, os investidores sociais têm hoje apoiado projetos específicos das OSCs que consideram relevantes e estratégicas, o que implica em novos desafios para a gestão dessas organizações, à medida que agora elas precisam suprir as demandas por recursos institucionais por intermédio de uma variedade de projetos, serviços e investidores, cada qual com regras e graus de flexibilidade distintos, envolvendo, desta maneira, uma complexa estrutura financeira e contábil que questiona e desafia seus sistemas de accountability e as capacidades de eficiência e eficácia organizacional (Lewis, 2006). 
Por isso, principalmente a partir da década de 1990, as OSCs viram-se obrigadas a repensar sua missão, sua forma de atuação, suas estruturas e seu funcionamento (Hudson, 1999; Rodrigues, 2003), num movimento que sabidamente levou essas organizações a tornarem-se semelhantes às organizações privadas com fins de lucro (Nanus, 2000), em função do propalado discurso managerialista de que as empresas são organizações mais eficientes e profissionalizadas (Chanlat, 1999; Parker, 2002), pois fundamentadas em funções técnicas objetivas e racionais que lhes garantem um funcionamento efetivo na ordem social do mercado capitalista (Clegg \& Hardy, 1996).

Nesse contexto, a Administração e suas teorias e práticas surgem como área de conhecimento potencialmente portadora de soluções para as deficiências gerenciais do terceiro setor (Coelho, 2002). Por um lado, conforme argumenta Voltolini (2003), o conhecimento em gestão configura-se como um instrumento útil a serviço da melhor consecução dos objetivos institucionais; representa uma espécie de "mapa de navegação" para as organizações do terceiro setor em ambientes cada vez mais complexos, de extensa multiplicidade de atores e papéis, de urgência de demandas por resultados e, sobretudo, sob a necessidade de se construir ações mais sustentáveis.

De outro lado, porém, devemos ressaltar que introduzir conceitos e práticas administrativas e organizacionais em OSCs é um desafio de vulto, pois, como alerta Serva (1997), as variáveis sempre comportam-se de maneira distinta nas organizações do terceiro setor, exigindo, portanto, releituras e adaptações compatíveis com as finalidades da atividade social. Essas adaptações, entretanto, nem sempre são feitas ou muitas vezes lembram remendos mal costurados de práticas empresariais (Voltolini, 2003), consubstanciados na visão gerencialista e posicionada de organização e de organizar (Chanlat, 1999; Böhm, 2006), cujo foco continua sendo em noções de eficiência, eficácia, clientela, qualidade, produtividade, estratégia e demais concepções do gênero. Conforme Lewis (2006), tal agenda de gestão tem tomado antes a forma de um gerencialismo imposto do que de uma agenda irrompida organicamente da dinâmica das próprias OSCs.

Para Chanlat (2002), o gerencialismo, ou managerialismo, refere-se a um sistema de descrição, explicação e interpretação do mundo a partir de categorias, noções e princípios administrativos e organizacionais da gestão estratégica privada, os quais, segundo o autor (2002, p. 2), têm "invadido amplamente as escolas, as universidades, os hospitais, as administrações, os serviços sociais, os museus, os teatros, as entidades sem fins lucrativos e até as igrejas", cristalizando-se de forma natural no cotidiano das pessoas. Assim, tanto o setor público quanto o terceiro setor tornam-se espaços para um esforço massivo em direção à “managerialização" (Esposito, Ferlie, \& Gaeta, 2017; Pollitt, 1993; Clarke \& Newman, 1997).

O resultado desta difusão do discurso gerencialista é a legitimação social e moral da empresa como forma organizativa dominante e referencial (Clegg \& Hardy, 1996), mediante um processo de posicionamento de uma dada visão de gestão, um sistema de ideias, práticas, conceitos, discursos e representações de administração que aqui designaremos como gestão estratégica, extrapolando formações históricas específicas para naturalizar-se no tempo e no espaço como uma concepção absoluta e predeterminada do quem vem a ser organização e organizar (Böhm, 2006).

Deste modo, partimos da premissa de que a gestão estratégica atualmente está posicionada hegemonicamente nas organizações em geral, disseminando uma versão de organização e gestão que é formal, racional e burocrática, de sorte que, para resguardar a previsibilidade e a dinâmica de controle (Böhm, 2006; Clegg, 1998; Parker, 2006; Chanlat, 1999), predominam nessa concepção tradicional de gestão características como a burocratização, o formalismo, o estabelecimento de normas e controles, a hierarquização da estrutura, o comando centralizado, a prevalência da razão instrumental, a racionalização e a divisão do trabalho, o processo de impessoalização dos indivíduos, a ênfase na capacidade adaptativa em relação a um ambiente de mudanças constantes (Tragtenberg, 2005, 2006; Kallinikos, 2004; Höpfl, 2006; Tenório, 2008; Bresser-Pereira \& Prestes Motta, 2004; Cançado, Sausen, \& Villela, 2013). 
Para Tenório (1999a, p. 99, grifos do autor), esse espectro de gestão estratégica há muito ronda o terceiro setor, pois, alega ele, “a procura de 'profissionalização' do [terceiro] setor tem, na realidade, objetivado mais a busca de estratégias de sobrevivência organizacional e (ou) de grupos do que a maior efetividade das suas ações como agentes sociais.

Neste diapasão, tem emergido no campo das OSCs no Brasil uma corrente denominada Desenvolvimento Institucional (DI), que, para além do mero aprimoramento técnico-gerencial das organizações à primeira vista, busca levar em conta seus posicionamentos nos ambientes nos quais elas estão inseridas e as intervenções para desempenharem, de forma relevante, legítima e sustentável os papéis a que se prestam. Trata-se de um suposto intento de preencher as lacunas deixadas às dimensões não contempladas pelas práticas, políticas e processos oriundos da concepção de gestão estratégica baseada na empresa. Suposto porque, conforme buscaremos discutir neste texto, restam dúvidas se esta nova perspectiva afasta-se mesmo dos pressupostos ontológicos e epistemológicos sobre os quais está fundada a gestão estratégica, em direção a uma possibilidade contra-hegemônica de desenvolvimento das instituições do terceiro setor (Girei, 2016), na perspectiva de uma gestão mais social.

De acordo com Armani (2001, p. 26), o conceito de DI “compreende os processos e iniciativas que visam assegurar de forma duradora a realização da missão institucional e fortalecer o posicionamento estratégico de uma determinada organização na sociedade". Ao longo das duas últimas décadas, acepções centrais nessa definição de DI, como sustentabilidade, legitimidade, ambiente institucional, fortalecimento e visão sistêmica, dão arrimo a uma série de projetos voltados a OSCs, numa tentativa de suplantação da impregnada noção de profissionalização e managerialização que marcou o setor desde a década de 1990. Conforme observa Dar (2007), muito do que está legitimado, estabelecido e difundido como padrões de boas práticas de desenvolvimento está de fato firmado no managerialismo, concebendo a gestão técnica como ferramenta neutra e racional para o progresso.

Por outro lado, o DI, na perspectiva aqui adotada, nasce com a pretensão de fomentar discussões acerca de dimensões até então descuradas pelas iniciativas de profissionalização técnica e gerencial, com debates e ações sobretudo em torno das dimensões sociopolítica e institucional. Segundo Armani (2001), a escassez de recursos e o gerenciamento do complexo conjunto das demandas referem-se somente a uma dimensão gerencial e contábil, que já constituem um drama cotidiano para muitas organizações do terceiro setor. No entanto, "a outra dimensão é política e institucional, dizendo respeito ao risco de redução da autonomia institucional e, no médio prazo, de mudança da própria identidade da organização” (Armani, 2013, p. 26).

No nosso entender, apesar de o institucionalismo constituir-se em temática recorrente já de longa data nos estudos organizacionais (Meyer \& Rowan, 1977; DiMaggio \& Powell, 1983; Peci, 2006; Carvalho, Vieira, \& Silva, 2012), o conceito de desenvolvimento institucional aqui em debate representa um tema relativamente novo na literatura do campo do terceiro setor. Cabe, portanto, refletir criticamente acerca da pretensa inovação que essa noção de DI parece trazer para o campo da gestão no terceiro setor no momento em que correntes como a gestão social emergem como críticas às teorias e práticas administrativas hegemônicas, circunscritas que estão no bojo da gestão estratégica (Tenório, 1998; Cançado, Tenório, \& Pereira, 2011).

A gestão social, por exemplo, alinhada à crítica da Escola de Frankfurt, começa a ganhar corpo como uma gestão não orientada para finalidades meramente econômicas, como uma linha de fuga em relação à ortodoxia positivista e à racionalidade utilitária da gestão estratégica (Cançado et al., 2011; França Filho, 2008). Por isso, o conceito de gestão social tem um grande potencial transformador e emancipatório (Subirats, 2007; Tenório, 2008), uma vez que almeja ser a antítese da gestão estratégica, na qual impera a razão instrumental voltada para o cálculo utilitário de consequências, e, em vez disso, visa outras lógicas de ação, mais sociais, políticas, culturais ou ecológicas (Tenório, 2008; França, 2008).

Partindo de tais delineamentos, o objetivo deste ensaio é, por meio de revisão de literatura, discutir se a proposta de desenvolvimento institucional em OSCs, na perspectiva proposta por Armani (2001, 2002, 2004, 2013), vai ao encontro dos pressupostos teóricos e conceituais da gestão social, tendo como 
fim imanente a emancipação dos sujeitos nessas organizações, ou se permanece arraigada nas premissas managerialistas dominantes da gestão estratégica. Em outras palavras, a problemática geral que orienta este texto é: Qual gestão impera nesse conceito de desenvolvimento institucional, uma gestão social ou uma gestão estratégica do social?

Como salienta Armani (2013), no Brasil e na América Latina em geral há uma carência de espaços e iniciativas para reflexão e análise teórica das práticas voltadas para o desenvolvimento institucional em OSCs. Nosso propósito, então, é contribuir para uma discussão ampliada e crítica dessa temática no bojo do campo da gestão no terceiro setor, com vistas a melhor compreender os constituintes teórico-conceituais da noção de DI, tendo como pano de fundo os referenciais da gestão social e da gestão estratégica.

\section{Desenvolvimento Institucional (DI) em OSCs}

Até meados da década de 1980, questões como governança, gestão, planejamento, avaliação, finanças, dentre outras, eram frequentemente relegadas a um segundo plano no âmbito das organizações do terceiro setor. Havia certa hostilidade por parte dessas organizações em relação à Administração, que era vista como um alien, um conjunto de ideologias e preocupações referentes um a universo estranho e externo (Lewis, 2006). Logo, a atenção era reduzida quanto a aspectos da dinâmica organizacional e institucional nas OSCs, sendo a institucionalização considerada meramente uma adequação àquelas exigências formais incontornáveis (Armani, 2013). Na opinião de Fernandes (1988), a cultura das OSCs era permeada por certo antiinstitucionalismo, haja vista que, naquele momento, a concepção era de que a institucionalidade implicava rigidez, centralização, burocratização. Além disso, o terceiro setor nasce de fora para dentro em relação ao Estado, sob impacto dos movimentos sociais aos quais apoiava (Falconer, 1999).

Não obstante, com as transformações culturais verificadas no contexto mundial e notadamente nas relações Norte-Sul a partir dos anos 1990, os organismos internacionais que apoiavam significativamente OSCs brasileiras passaram a atuar com maior rigor na seleção das instituições e programas financiados (Silva, 2010) e a reagir mais firmemente em relação ao grau de informalidade e instabilidade das organizaçóes e movimentos sociais nos quais investiam, exigindo dessas entidades maior capacidade de elaborar, executar e gerenciar projetos, aplicar recursos, prestar contas e demonstrar resultados como requisitos básicos para o financiamento das ações. Ademais, paulatinamente o caráter dos financiamentos e da cooperação mudou, passando do apoio às organizações em si para o investimento em projetos e açóes específicas e para a contratação de serviços (Armani, 2013; Ávila, 2013), sendo a capacidade institucional e de gestão apontadas como um fator primordial para a sustentabilidade dos projetos (Dar, 2007).

Nesta mesma linha de raciocínio, surgem situações em que as OSCs tornam-se coautoras, ou meras executoras, de projetos junto a grandes empresas, o que a princípio não seria problema não fossem as inúmeras ocasiões em que essas organizações sociais acabavam perdendo a autonomia e a autoria política e intelectual das iniciativas para ganhar o status de operadoras de ações alheias, comprometendo sua relevância social no campo (Armani, 2013). Nesses casos, o discurso de sustentação da proposta das OSCs é baseado na responsabilidade social, mas seus propósitos são ações sociais em campos nos quais possam capitalizar resultados de imagem e também financeiros, para as empresas mantenedoras, projetando-as como entes comprometidos com o meio envolvente e que buscam soluções socialmente sustentáveis e responsáveis (Caetano, Brandão, Duarte, Leal, \& Gouveia, 2011).

Não bastasse isso, o discurso managerialista e seus postulados, tais como agilidade, pragmatismo, funcionalidade e resultados de curto prazo, passam a impregnar cada vez mais o ambiente contextual no qual as OSCs estão inseridas, colocando em questão a própria credibilidade dessas organizações no que tange a sua capacidade de atuação (Chanlat, 2002; Armani, 2013; Lewis, 2006). Tal retórica gerencialista no terceiro setor é ainda afirmada por inúmeras vozes acadêmicas (Girei, 2016), que compartilham da visão de que uma gestão científica baseada no business pode contribuir para a missão das organizações sociais por meio do 
aprimoramento dos seus sistemas de desenvolvimento. Assim, emergem no terceiro setor diversas correntes e iniciativas de profissionalização e aprimoramento organizacional de inspiração mercadológica, com o intuito de transformar as OSCs em estruturas tecnicamente mais eficientes e eficazes.

Segundo Armani (2013), esse foco maior nas dimensões técnica e gerencial do desenvolvimento social pouco a pouco acarretou uma diminuição do protagonismo das OSCs perante seus financiadores, posto que muitas delas passaram a ter, grosso modo, menos recursos, menos autonomia na tomada de decisão e mais mecanismos de controles externos. Além disso, "pode-se perceber a projeção de certa cultura empresarial orientada por resultados materiais de curto prazo para a área social, nem sempre com efeitos virtuosos" (Armani, 2013, p. 30).

A qualificação técnica das OSCs em relação ao que fazem e aos processos gerenciais é, decerto, um dos principais desafios do terceiro setor. Significa dizer que a busca por prestar bons serviços e executar eficientemente bem seus projetos não representa, por si, um problema para a legitimidade das OSCs. O problemático, ressalta o autor, é assumir que esses objetivos são suficientes para definir suas identidades e o sentido de suas existências, assim como para garantir o protagonismo dessas organizações na defesa de direitos e do interesse público da sociedade (Armani, 2013). A apropriação acrítica e natural do managerialismo contribui nesse processo, na medida em que ele se impóe sobre formas alternativas de gestão e pressionam as organizações a excluírem uma identidade coesa, positiva e autônoma em suas relações com apoiadores (Dar, 2007).

Nesse sentido, é na virada da década de 1980 para os anos 1990 que a temática do desenvolvimento institucional é incorporada nas OSCs brasileiras, a partir do termo institutional building, cuja origem, na década de 1960, remete aos esforços dos organismos de cooperação internacional dos países do hemisfério norte em promover a capacitação das organizações do Sul global (Lewis, 2006). Assim, o DI, também conhecido por terminologias como fortalecimento institucional ou capacity building, aparece como iniciativa de desenvolvimento social por meio do fortalecimento de uma nova institucionalidade das OSCs, em resposta à necessidade de instituições locais (nacionais) sólidas para contribuir para com o desenvolvimento dos países, ganhando força no cenário das organizações sociais precisamente ao final da década de 1990 (Armani, 2013; Bossuyt, 2001; Ávila, 2013).

O fortalecimento de uma nova institucionalidade significa ter em conta que o desenvolvimento das organizações se dá por meio de contínuos processos de adaptação e mudança que contemplem tanto fatores internos - tais como visão, missão, liderança, estruturas e processos de gestão, recursos, desempenho, etc. quanto fatores externos de capacidade - associados a aspectos políticos e de governança, valores e normas sociais gerais, quadro jurídico-administrativo e condições socioeconômicas (Antlöv, Brinkerhoff, \& Rapp, 2010). Por isso, explica Armani (2013, p. 61), a abordagem do DI “tem a pretensão de contribuir com a leitura do movimento das organizações, tanto em sua dinâmica interna como externa”, para que possam enfrentar os desafios do ambiente e conquistar sua perenidade.

Neste sentido, pautado numa perspectiva de integralidade, o processo de DI refere-se ao fortalecimento da capacidade das organizações de realizarem a sua missão, da sua identidade política e do impacto de suas ações de forma duradoura, por meio de um conjunto de esforços e mudanças qualitativas na organização, no que tange a princípios, paradigmas, relações e mesmo estrutura (Armani, 2002). No entender de Armani (2013), o DI exprime uma abordagem sistêmica e integrada do desenvolvimento das organizações, realçando a sinergia entre o desenvolvimento organizacional, de caráter interno, e a projeção institucional, externa, da organização no espaço público. Nessa medida, defende o autor, o DI se diferenciaria de abordagens gerencialistas, usualmente focadas em questões técnicas e de desempenho.

Acresce observar que a utilização de acepções como "instituição" ou "institucional" faz alusão às dimensões mais estruturantes e perduráveis das organizações em campos de interação social, pois as organizações existem e atuam no interior de ambientes institucionais amplos, isto é, dentro de certas institucionalidades vigentes 
em uma sociedade (Armani, 2013). Logo, o conceito de DI não diz respeito unicamente ao desenvolvimento de organizações, mas refere-se antes ao fortalecimento de organizações enquanto instituições.

Isto quer indicar que o que se busca desenvolver e aprimorar não é somente a dimensão da performance das ações e da gestão das organizações (capacidades, estruturas, gestão, procedimentos, instrumentos), mas também sua dimensão sociopolítica (identidade, base social, cultura organizacional, comunicação, protagonismo no espaço público, alianças e padrões de interação, etc.). Isto é, sua capacidade de contribuir para a mudança da institucionalidade na qual se situa (Armani, 2013, p. 67).

No bojo dessa definição de DI no campo das OSCs, a noção de sustentabilidade tem papel nuclear, porque está intimamente associada ao fortalecimento do caráter permanente e dinâmico das OSCs. Para Armani (2004, p. 11), "a sustentabilidade de uma organização é a capacidade de sustentar de forma duradoura o valor social de seu projeto político-institucional, a partir da interação criativa com contextos mutáveis”. Desse modo, tal conceito de sustentabilidade não se limita à lógica reducionista e impositiva centrada no domínio da sustentação econômico-financeira ou ao bom desempenho e ampliação das capacidades organizacionais (Araújo, Melo, \& Schommer, 2005), mas abarca um conjunto bem mais extenso de aspectos subjacentes ao fortalecimento institucional das OSCs na busca pela sua legitimidade e longevidade no campo social (Armani, 2004).

Estes delineamentos esclarecem que a corrente aqui em discussão, embora relacionada a elas, não se confunde com outras correntes de desenvolvimento organizacional e capacity building. De acordo com Franks (1999), um programa de desenvolvimento institucional está essencialmente direcionado à continuidade de uma entidade organizacional a partir de padrões estáveis e recorrentes de comportamento validados por seus usuários. Capacity building, por seu turno, focaliza primordialmente o desenvolvimento de recursos humanos e o fortalecimento dos sistemas gerenciais e dimensões organizacionais com vistas a fomentar e aprimorar as capacidades e habilidades da organização (Biswas, 1996; Lewis, 2006). Ademais, historicamente, este conceito incorpora tanto as tendências managerialistas na formação das agendas do terceiro setor (vide as inúmeras empresas de consultoria e websites de treinamento para organizações não governamentais [ONGs]) quanto os pressupostos dominantes que caracterizam as relações desiguais e de dependência das organizações do Sul e do Norte, no que tange aos debates sobre poder e autonomia (Lewis, 2006), visto ser essa noção frequentemente usada com referência aos esforços externos de fortalecer os governos e o setor público em países em desenvolvimento (Polidano \& Hulme, 1999). Tratar-se-ia, portanto, de uma noção limitada, centrada num paternalismo sutil associado à visão meramente instrumentalista das OSCs como prestadoras de serviços a fundos de doadores (Fischer, 1994).

Neste caso, podemos entender o DI em OSCs como uma perspectiva ampliada que contempla dois enfoques a ele inerentes: $\mathrm{O}$ primeiro deles pode ser definido como enfoque técnico-gerencial, no qual são privilegiados os desafios de gestão e as condições de eficiência e eficácia, havendo, nesse caso, uma preocupação com a profissionalização da organização por intermédio de categorias como planejamento estratégico, sistema de monitoramento e avaliação com base em indicadores, mobilização de recursos, marketing, gestão administrativo-financeira e capacitação técnica dos profissionais. Há, nesse enfoque, uma aproximação em relação às abordagens de desenvolvimento organizacional e capacity building. No segundo enfoque, denominado enfoque sociopolítico, por outro lado, estaria integrada a dimensão gerencial, articulada, porém, à dimensão sociopolítica na qual a organização se insere, envolvendo sua base social, legitimidade, credibilidade, transparência, rede de interlocução e ação conjunta com OSCs e Estado, sua autonomia e sua capacidade de oferecer serviços de qualidade e, sobretudo, de promover processos de mudança social e de influenciar o ambiente político (Armani, 2001; Fowler, Campbell, \& Pratt, 1992; Lewis, 2006).

O que nos interessa discutir, daqui em diante, é se essa perspectiva teórica e conceitual do DI, considerando seus dois enfoques, aponta para um reposicionamento dos discursos e práticas managerialistas da gestão estratégica em direção à proposta da gestão social, cuja finalidade é a emancipação dos sujeitos nas organizações via ações dialógicas verdadeiramente participativas, intersubjetivas e baseadas na racionalidade 
comunicativa. O fortalecimento das instituições do terceiro setor que propõe a corrente de desenvolvimento institucional representa uma oportunidade contra-hegemônica e alternativa para inserção de pressupostos de uma gestão social no contexto das OSCs? Em que medida o DI busca questionar a lógica da gestão privada do mercado como embasamento das ações das organizações do terceiro setor? Ou permanece o DI como mais uma iniciativa de gestão estratégica do social?

\section{Gestão Estratégia e Gestão Social}

Para seguirmos na discussão proposta, é essencial explicitarmos o que vem a ser gestão social, cuja compreensão, contudo, não pode estar desvinculada dos pressupostos epistemológicos da teoria crítica frankfurtiana, sobretudo no que concerne à contraposição entre a teoria tradicional e a teoria crítica colocada pelos filósofos da Escola de Frankfurt. Cabe registrar, antes de tudo, que os argumentos orientativos desta discussão estão alinhados aos postulados teórico-conceituais da corrente de gestão social encabeçada por Tenório (1999a 1999b, 2005, 2008, 2012) e seus adeptos (Cançado, Pereira, \& Tenório, 2013; Cançado et al., 2011; Cançado et al., 2013a), corrente que consideramos como a mais representativa no campo da Administração (Justen \& Moretto, 2013).

Para os frankfurtianos, a teoria tradicional está fundamentada em todo conhecimento de cunho positivista, onisciente e acrítico, que enfatiza o empirismo das ciências naturais, a verificação e identificação daquilo que se pode mensurar, observar e provar como forma de compreender a realidade. Tal epistemologia reifica os fatos sociais ao considerá-los análogos aos fenômenos naturais e, por isso, a teoria tradicional não tem compromisso com a transformação social, senão com a manutenção do status quo (Tenório, 1998; Horkheimer, 1990).

Tenório (1998, p. 11) resume a teoria tradicional afirmando que ela é "inadequada para analisar ou entender a vida social", isto é, que ela "analisa somente o que vê e aceita a ordem social presente, obstruindo qualquer possibilidade de mudança, o que conduz ao quietismo político", além de estar "intimamente relacionada à dominação tecnológica na sociedade tecnocrática [em] que vivemos".

Partindo de tal constatação, Tenório (1998) relaciona a teoria tradicional à gestão estratégica alegando que o campo da gestão organizacional está intimamente associado ao pragmatismo, ao sucesso de mercado e à razão instrumental, que constituem os pilares do discurso managerialista hoje dominante (Chanlat, 2002; Parker, 2006; Clegg \& Hardy, 1996). Segundo Tenório (1998, p. 14), "a gestão estratégica é um tipo de ação social utilitarista, fundada no cálculo de meios e fins e implementada através da interação de duas ou mais pessoas, na qual uma delas tem autoridade formal sobre a(s) outra(s)". Esse tipo de ação gerencial é típico dos sistemas empresariais na determinação de suas condições de funcionamento e também dos aparelhos do Estado em suas imposições perante a sociedade.

A gestão social, por sua vez, pode ser concebida como uma corrente contra-hegemônica no pensamento administrativo, pautada numa epistemologia crítica que busca reconstruir o conhecimento por meio da produção social intersubjetiva, e não como resultado de saberes oniscientes. Assim, se a gestão estratégica corresponde à teoria tradicional, a gestão social é partidária de elementos teórico-epistemológicos críticos, cujo princípio norteador é a busca pela emancipação humana. Neste sentido, Tenório (1998, p. 9) argumenta que as teorias críticas "visam produzir esclarecimento entre os agentes que as defendem, [...]capacitando esses agentes a estipular quais são os seus verdadeiros interesses", uma vez que "elas são inerentemente emancipatórias, isto é, elas libertam os agentes de um tipo de coerção que é, pelo menos parcialmente, autoimposto, a auto-frustração da ação humana consciente"; ademais, essas teorias são reflexivas e não objetificantes.

Neste contexto, ao invés de basear-se na lógica do mercado, como o faz a gestão estratégica, a gestão social é alicerçada em questões de natureza social, ou seja, visa atender o bem comum da sociedade (Tenório, 1998). Para tanto, Tenório (2008) encontra na razão comunicativa do filósofo tardio da Escola de Frankfurt, 
Jürgen Habermas, a possibilidade de emancipação do homem e da sua autonomia social. É nesse sentido que se institui a gestão social, contrapondo a "gestão tecnoburocrática, monológica, por um gerenciamento mais participativo, dialógico, no qual o processo decisório em uma dada sociedade é exercido por meio dos diferentes sujeitos sociais" (Tenório, 1999b, p. 151).

Na perspectiva da gestão social, a ação estratégica almeja apenas aquiescência dos sujeitos, haja vista que os objetivos são previamente definidos pelos grupos dominantes e os demais atores são meros coadjuvantes na cena social. Como diria Freire (1987), na situação de dominação uma elite dominadora sempre prescreve e os dominados seguem as prescrições. A ação gerencial dialógica da gestão social, por seu turno, visa alcançar o consenso intersubjetivo resultante da atuação comunicativa dos diversos atores (Gondim, Fischer, \& Melo, 2006), sendo as ações orientadas pela racionalidade comunicacional da proposta habermasiana, como observamos na seguinte colocação:

Sob a concepção de ação gerencial dialógica, a palavra-princípio democratização seria implementada por meio da intersubjetividade racional dos diferentes sujeitos sociais - subordinados e superiores - dentro das organizações. Essa intersubjetividade racional pressupõe que os atores, ao fazerem suas propostas, têm de apresentá-las sob bases racionais, quer dizer, nenhuma das partes - superiores e subordinados - pode impor suas pretensões de validade sem que haja um acordo alcançado comunicativamente, por meio do qual todos os participantes expóem os seus argumentos mediados linguisticamente em busca do entendimento (Tenório, 2005, p. 120, grifos do autor).

Pimentel e Pimentel (2010) elencam sete princípios gerais acerca da gestão social:

1) A gestão social tem como objetivo precípuo o interesse coletivo de caráter público;

2) O interesse público, portanto, é a orientação de valor da gestão social;

3) A gestão social pressupõe a subordinação da lógica instrumental a um processo decisório deliberativo, enquanto busca atender às necessidades de dado sistema social;

4) A gestão social congrega e envolve todos os atores sociais, organizacionais e institucionais de um determinado espaço;

5) A gestão social é um processo participativo, dialógico e consensual;

6) A gestão social materializa-se na deliberação coletiva alcançada pelo consenso possível gerado pela argumentação livre de coerções;

7) As parcerias e redes intersetoriais são formas de conceber e operacionalizar a gestão social, tanto em termos de práticas como de conhecimentos.

Cançado et al. (2011) delimitam o conceito de gestão social propondo-a como um processo coletivo de tomada de decisão, escoimado de coerção, fundado na inteligibilidade da linguagem, na dialogicidade e no entendimento esclarecido como processo, na transparência como pressuposto e na emancipação como finalidade imanente. Em resumo, tratar-se-ia de um processo dialógico em que os participantes da ação compartilham da autoridade decisória, o que aponta para a tomada coletiva de decisão (Tenório, 1999b). Sendo, portanto, a participação a essência da gestão social, tal perspectiva de gestão demanda inerentemente a participação igualitária dos atores sociais na definição das decisões (Cançado et al., 2013a).

O que nos importa refletir a partir dos argumentos aludidos até aqui é o fato de que a gestão social se apresenta como um campo de conhecimentos e práticas que converge para o verdadeiro sentido das OSCs, que, para Tenório (1999a, p. 91), "deve ser estudado e planejado numa perspectiva da emancipação do homem, do cidadão, e não sob o enfoque de 'consumidor', 'cliente', 'meta' ou 'alvo' a ser atingido", conceitos típicos da empresa capitalista e do Estado burocrático. Sem embargo, é importante reconhecer também que o discurso managerialista amplia cada vez mais a tendência de o terceiro setor ter sua missão e suas ações planejadas, executadas e avaliadas sob a égide das tecnologias gerenciais embasadas na lógica do mercado capitalista, promovidas como soluções neutras e naturais para o combate à pobreza e à desigualdade a partir do aumento da efetividade das organizações sociais (Girei, 2016).

Conforme sugere Tenório (1999a, p. 95), 
Já ocorre de organizações não-governamentais participarem de concorrências públicas, por um lado, e, de outro, submeterem seus projetos a agentes econômicos, correndo o risco de uma proposta de ação social transformar-se em uma metodologia de submissão às possíveis estratégias desses tipos de agentes.

Nesse contexto, é notável que novas correntes de gestão surjam no campo do terceiro setor sem questionar os princípios centrais da abordagem da gestão estratégica dominante, como, por exemplo, relações de poder, dominação e opressão entre os sujeitos, centralidade do mercado, heteronomia nos processos decisórios, predomínio da razão instrumental utilitária, entre outros. Diante disso, como, então, se posiciona a proposta do desenvolvimento institucional em OSCs, ao menos no que tange aos seus principais delineamentos teórico-conceituais?

\section{DI como Gestão Social ou Gestão Estratégica do Social?}

Num primeiro momento, é possível aludirmos que o conceito de desenvolvimento institucional em OSCs possui alguns elementos teórico-conceituais promissores que lhe aproximam da proposta da gestão social. $\mathrm{O}$ primeiro deles diz respeito ao protagonismo das OSCs no espaço público, na medida em que o DI visa ampliar o impacto das organizações no desenvolvimento social e na persecução dos interesses coletivos (Armani, 2013). Como vimos anteriormente, o interesse público bem compreendido, e não o interesse particular da pessoa privada, é o valor que orienta a gestão social (Pimentel \& Pimentel, 2010; Tenório, 1999a).

Neste sentido, a perspectiva do DI leva em conta que um dos principais desafios das organizações do terceiro setor, em termos de identidade e autonomia, é manter sua capacidade de exercer protagonismo na esfera social, no que se refere aos interesses públicos da sociedade e à defesa da democracia (Armani, 2013). O fortalecimento institucional, nesse caso, contribui para a ampliação da projeção institucional das organizações no âmbito do espaço público, além de priorizar a tomada de decisão autônoma das OSCs em relação a outras organizações com as quais mantêm intercâmbio. Podemos afirmar, portanto, que OSCs institucionalmente fortalecidas ampliam sua capacidade de identificação, problematização e proposição de soluções para problemas sociais no interior das esferas públicas, espaços nos quais, sob a ótica da gestão social, os assuntos de interesse público são tematizados e deliberados pelos diversos atores sociais, com vistas a influenciar ações e políticas executadas pelos aparelhos de governo e da administração pública (Tenório, 1998, 1999a; Morrow \& Torres, 2003).

Um segundo aspecto está relacionado ao potencial de interlocução e articulação das OSCs com outros atores sociais. Tal aspecto coaduna com a ação gerencial dialógica da gestão social, que busca sempre alcançar o consenso intersubjetivo resultante da atuação comunicativa dos diversos atores (Gondim et al., 2006). Assim, o DI, ao pretender ir além do desenvolvimento organizacional, considera central para as OSCs o estabelecimento de redes de comunicação e ação conjunta nas esferas públicas, com vistas a promover o diálogo e a interação dessas organizações junto aos poderes administrativos do Estado, à mídia e às empresas privadas para a consecução de suas missões institucionais (Armani, 2001). Um processo de DI, particularmente em sua dimensão social e política, envolve a construção de uma base social por meio de diversificadas formas de envolvimento, como alianças e parcerias, participação ativa e relevante em espaços e fóruns de discussão, campanhas, mobilização de atores locais e regionais (Armani, 2013). Essa perspectiva vai potencialmente ao encontro dos pressupostos teórico-conceituais da gestão social, notadamente os princípios da inclusão, do pluralismo, da igualdade participativa, da autonomia e do bem comum, que conferem legitimidade aos processos de discussão e ação política em prol de uma finalidade comum, nos quais as OSCs desempenham um papel central.

Não obstante, tais elementos sejam indicativos importantes acerca do presumível alinhamento do DI aos princípios de uma gestão social, outros fatores, porém, merecem ser também analisados antes de decretarmos o DI como uma perspectiva deveras antinômica ao discurso dominante de organização e organizar que impera hoje no terceiro setor, qual seja, a gestão estratégica (Tenório, 1999a). Como já salientamos, nossos 
argumentos têm arrimo numa epistemologia crítica, e isso implica refletir sobre certos pontos que julgamos essenciais.

Em primeiro lugar, devemos reforçar que os processos gerenciais do terceiro setor não podem ser pautados pela lógica do mercado, em detrimento de uma solidariedade comunitária (Tenório, 1998). Isso porque, afirma Tenório (1999a), não é de hoje que se tem tentado transpor as tecnologias do setor privado ao campo das OSCs. Para o autor (1999a, p. 98), isso denota uma contradição em si, "porque a característica central da gestão do setor privado é definida e identificada como gestão estratégica”, e, desta feita, as OSCs devem atuar sob uma epistemologia distinta daquela do mercado. Assim,

Enquanto o segundo setor [empresa] atua através do enfoque monológico, estratégico, no qual suas ações são calculadas e utilitaristas, implementadas através da interação de duas ou mais pessoas, na qual uma delas tem autoridade formal sobre a(s) outra(s), o terceiro setor deve atuar numa perspectiva dialógica, comunicativa, na qual suas ações devem ser implementadas por meio da intersubjetividade racional dos diferentes sujeitos sociais a partir de esferas públicas em espaços organizados da sociedade civil [...] (Tenório, 1999a, p. 100, grifos do autor).

Destarte, as parcerias entre OSCs e empresas com fins lucrativos sempre devem ser orientadas por reflexões críticas acerca das implicações de tal cooperação. Embora as parcerias e redes intersetoriais sejam fontes de operacionalização de uma gestão social (Pimentel \& Pimentel, 2010), e estas sejam estimuladas constantemente no enfoque sociopolítico do desenvolvimento institucional, não devemos esquecer que há uma tendência da lógica estratégica do mercado em invadir os domínios das organizações do terceiro setor, alterando, inclusive, suas próprias identidades e princípios. Como reconhece Armani,

Tanto gestores públicos como gerentes de institutos e fundações privadas e de ONGs necessitam de um "outro" para dialogar, para estabelecer parcerias, para validar suas iniciativas e para servir como referência de resultados. Quanto mais este outro for colocado na posição de ator coadjuvante e colaborador operacional nos processos, tanto mais decrescente tenderão a ser a legitimidade e a efetividade das ações desenvolvidas no longo prazo (Armani, 2013, p. 31).

Tenório (1999a) observa que as OSCs não podem desempenhar apenas funções intermediárias entre os anseios da sociedade e do Estado, mas devem reforçar seu compromisso e relevância com a problematização e solução de questões sociais. Ademais, é preciso sempre manter cautela no que concerne à permanência das organizações empresariais em ações voltadas ao social, afinal, não é incomum que no primeiro momento de crise, ou por conta de dificuldades financeiras ou devido a mudanças estratégicas e mercadológicas, empresas modifiquem suas políticas com relação à "área social” e cortem seus investimentos corporativos em projetos dessa natureza.

Outra questão que, no nosso entender, fragiliza o conceito de DI como possível antimodelo ao discurso e práticas organizacionais dominantes no terceiro setor é a conspícua visão naturalizada de gestão que prevalece na literatura e nas ações de DI no campo. Conforme alegamos anteriormente, a noção atualmente hegemônica de organização é marcada pelo pragmatismo e pelo gerencialismo (Böhm, 2006), este último considerado por Parker (2002) como um princípio organizacional universal, emergido como uma tecnologia generalizada de controle. Nesse particular, Misoczky e Vecchio (2006) destacam que hoje vivemos num tempo em que o gerencialismo mercadológico apresenta-se como uma utopia em plena realização e que não nos permite pensar o diferente. Há uma ideia posicionada que se manifesta num argumento tautológico comum nesse cenário: "As alternativas não são possíveis porque não funcionam” (Misoczky \& Vecchio, 2006, p. 10).

Neste sentido, Misoczky e Vecchio (2006, p. 7) adotam uma reação crítica acerca da ortodoxia posicionada dos estudos organizacionais, argumentando que é preciso transcender à "definição teleológica de organização como coordenação racional de atividades de um certo número de pessoas para atingir objetivos comuns e metas explícitas", por meio da divisão do trabalho e das funções, da hierarquia de autoridade e responsabilidades, e assim por diante. A concepção hegemônica de organização traz impregnada a ideia de 
um tipo específico de organização, a empresa, o que reflete um reducionismo que, por sua vez, é "inerente à racionalidade teleológica moderna” (Solé, 2003 como citado em Misoczky \& Vecchio, 2006, p. 7).

Nesse contexto, há diversos conceitos do mainstream empresarial frequentemente presentes na perspectiva do DI, como, por exemplo, estratégia de ação, planejamento institucional, organograma, mecanismos regulares de monitoramento e avaliação de desempenho, objetivos e resultados, indicadores, gerenciamento de pessoas, qualidade, adaptação, dentre outros (Armani, 2013). Com o fito de exemplificar como esses conceitos contribuem para que o DI convirja para os pressupostos da gestão estratégica, no que se refere particularmente à discussão aqui proposta, reproduzimos a seguir trechos de produções literárias recentes que relatam experiências de gestores de OSCs em processos de DI que têm sido formulados e conduzidos em diversas organizações do campo social no Brasil, os quais podem ser conferidos detalhadamente em Armani (2013).

O objetivo geral do projeto era "fortalecer a sustentabilidade da [Organização X] e as OCBs investindo na melhora das capacidades técnicas, financeiras e políticas, permitindo maior eficiência e eficácia em suas gestões" (Armani, 2013, p. 190, grifo próprio).

Neste sentido, o Projeto $[\mathrm{Y}]$ surgiu com o desafio de desenvolver competências organizacionais, a fim de manter a sustentabilidade da [Organização W] e aprimorar com eficiência sua gestão. [...] mudar era preciso, mas que, sobretudo, era também necessário planejar, avaliar, construir e desconstruir para alcançar com eficiência os objetivos (Armani, 2013, p. 228, grifo próprio).

No plano da sustentabilidade institucional tem-se preconizado as parcerias de longo prazo, em termos de desenvolvimento da organização, capacitação da gestão e mobilização de recursos (Armani, 2013, p. 127, grifo próprio).

[...] o primeiro passo foi uma reunião de planejamento estratégico para construção coletiva da visão, missão e valores institucionais (Armani, 2013, p. 164, grifo próprio).

Assim, com a chegada dos novos membros da equipe, as tarefas foram divididas, políticas e procedimentos foram descritos e um maior nível de profissionalização passou a ser exigido. O processo decisório, antes totalmente assistemático e horizontal, foi revisto, tornando-se mais racional e analítico. Um organograma baseado nas funções foi desenhado. Não era mais possível gerir a instituição tendo todos envolvidos em todos os processos e decisões. Foi preciso delegar, adaptar, reinventar, flexibilizar e ajustar, tudo ao mesmo tempo (Armani, 2013, p. 166, grifo próprio).

O risco instalado em processos que buscam ampliar a consistência organizacional está na simplificação desta questão e na produção de intervenções de manual, prescritivas do step by step e aprisionadas exclusivamente em ferramentas de gestão. Ainda que fundamentais na operação institucional, a abordagem restrita à instrumentalização gerencial opera como força alienante da natureza política do conceito de "desenvolvimento institucional" que se encontra filiado a uma matriz que saúda processos de transformação coletiva (Armani, 2013, p. 289, grifo próprio).

Não bastasse isso, o foco do desenvolvimento institucional na capacitação das OSCs para responderem e conduzirem processos de adaptação e mudança parece definitivamente afastar o DI da gestão social, cuja preocupação maior é a emancipação dos indivíduos, em direção às primeiras vertentes do institucionalismo, isto é, às correntes da teoria institucional mais voltadas à análise da adaptação organizacional, do isomorfismo institucional e da legitimação das organizações no ambiente (Carvalho, Vieira, \& Goulart, 2005; Meyer \& Rowan, 1977; Dimaggio \& Powell, 1983).

Como vimos, Armani (2013, p. 62) entende que "quanto mais consciente sobre como se dá seu movimento de adaptação e mudança, mais uma organização será capaz de enfrentar os desafios do contexto e lutar por sua perenidade". Não obstante as virtudes de tal abordagem, ela em geral implica o predomínio de uma racionalidade instrumental, na medida em que a ênfase reside na utilização de critérios técnicos para avaliar as consequências das decisões às demandas do ambiente (Astley \& Van de Ven, 2005). 
Acresce salientar, ainda, que a noção de sustentabilidade trabalhada no DI parece não incluir aspectos inter e transdisciplinares e, portanto, poderia ser questionada (Boeira, Pereira, \& Tonon, 2013). Tal noção de sustentabilidade apoia-se numa visão antropogênica ao desconsiderar a importância do ambiente natural e numa racionalidade também instrumental, pois seu intento é a sobrevivência. Além disso, a própria noção de legitimidade também acaba se tornando um recurso para a sustentabilidade das organizações, haja vista as instituições tidas como legítimas terem maior possibilidade de sobrevivência do que aquelas não legítimas (Rossoni, 2012).

Por fim, consideramos que a perspectiva de DI em OSCs, mesmo ao contemplar dimensões que não se limitam ao gerencial, endossa o discurso dominante de gestão ao não questionar práticas inerentemente estratégicas. Contudo, de acordo com Tenório (1999a, p. 91), a epistemologia sobre a qual deve se alicerçar o terceiro setor e, nesse caso, a própria corrente de DI ora em debate, deve destacar a necessidade "de a práxis social estar voltada para um conhecimento reflexivo e de uma práxis política que questione as estruturas sóciopolítico-econômicas existentes". Sem embargo, vemos que nenhum dos enfoques de DI parece oferecer um questionamento efetivo das relações de dominação e das ideologias subjacentes à concepção tradicional de organização e de organizar, o qual é fundamental pelo menos no âmbito do posicionamento crítico da gestão social.

\section{Considerações Finais}

Embora os argumentos aqui defendidos precisem ser devidamente aprofundados, não podemos nos regozijar com os sofismas como os que apregoam que, em primeiro lugar, a adoção de modelos estratégicos e a busca por eficiência são aceitáveis porque visam melhor atingir os fins sociais das OSCs, isso significaria meramente admitir e justificar o uso de certos meios por fins considerados nobres (Parker, Cheney, Fournier, \& Land, 2014). Em segundo lugar, de que a perspectiva do DI não nasceu com a pretensão de promover o reposicionamento crítico tal como discutimos anteriormente, e, portanto, não faria sentido esperar nada da noção de DI em OSCs que convirja para essa direção.

Contudo, cremos que é justamente por isso que cabe a reflexão acerca de pretensas novidades que nem sempre implicam em novidades. Dito de outro modo, abordagens recentes como a do DI, dentre tantas outras que volta e meia surgem no campo do terceiro setor, parecem longe de indicar qualquer iniciativa de reposicionamento da concepção estratégica e de gestão, pois continuam alicerçadas nas mesmas premissas do discurso gerencialista dominante. Em outras palavras, percebe-se uma afinidade eletiva, para usar a expressão weberiana, entre as práticas de DI em OSCs e gestão estratégica, sendo a última o fundamento epistemológico da primeira.

Diante disso, não nos cabe outra conclusão senão a de que a nova onda de desenvolvimento institucional aproxima-se mais de uma gestão estratégica do social do que uma gestão social. Parece-nos que os constituintes teórico-conceituais da noção de DI em OSCs descambam para a ortodoxia do managerialismo, pois preservam na sua essência uma preocupação com o desempenho organizacional e institucional, cuja lógica materializa-se mediante o aprimoramento de técnicas e processos de gestão, de adaptação e na busca por legitimidade como requisito de sustentabilidade, ou, em outras palavras, de sobrevivência institucional.

Ainda que tenha como proposta inicial transpor a noção de profissionalização gerencial das organizações do terceiro setor, essa perspectiva de DI o faz somente inserindo a noção de ambiente institucional na estratégia das organizações e, nessa medida, aproxima-se mais da teoria institucional (e isso merece investigação) do que da gestão social.

Convém esclarecer, finalmente, que não pretendemos renegar a importância da dimensão gerencial nas organizações do terceiro setor, mas discutir e refletir sobre a inspiração eminentemente gerencialista que orienta as concepções e práticas de organização e gestão no campo das OSCs, bem como alertar para a 
existência de outras possibilidades e alternativas organizacionais não hegemônicas, como a própria gestão social.

Em outras palavras, defendemos a necessidade de inserção e intensificação de abordagens críticas no campo estudado que homenageiem a busca pela emancipação humana nessas organizações. Não é incomum depararmo-nos com casos em que, por exemplo, uma ONG ambientalista combate a exploração desenfreada e o domínio antropogênico sobre os recursos naturais, ou um movimento feminista contestador da dominação do homem sobre a mulher nos diversos espaços sociais, mas que, no interior de suas paredes, no seu âmbito organizacional burocrático e na sua forma de gestão estratégica, não chegam a refletir e nem questionar as assimetrias de poder e as relações de repressão e exploração entre os indivíduos que nelas atuam; estas são, porém, relações tão predatórias quanto aquelas contra as quais levantam suas bandeiras e buscam combater nas suas atuações sociais.

Sem embargo, há de se destacar que, ao abarcar a dimensão sociopolítica, o compromisso com a mudança social e a predisposição para renovação, as ações de DI potencialmente conferem espaços promissores para práticas comunicativas, reflexivas e emancipatórias de uma gestão social. Como alternativa ao mainstream organizacional, a gestão social pode oferecer as categorias teórico-analíticas mais adequadas à concepção e avaliação do desenvolvimento institucional em organizações do terceiro setor, que, por sua vez, pode se constituir em um processo facilitador ou viabilizador dessa perspectiva de gestão. Tal enfoque, entretanto, necessita ser mais bem explorado pelos estudiosos e gestores que lidam com o conceito. Fica o convite àqueles que se interessarem pelo desafio.

\section{REFERÊNCIAS}

Abdala, D. O. S., Assis, L. B., Gonçalves, C. A., Abdala, R. A. (2015). Parcerias entre organizações do terceiro setor: perspectivas e desafios em dois hospitais de Belo Horizonte e Brasília. Administração Pública e Gestão Social, 7(4), 187-196.

Antlöv, H., Brinkerhoff, D. W., \& Rapp, E. Civil society capacity building for democratic reform: experience and lessons from Indonesia. Voluntas, 21(3), 417-439.

Araújo, E. T., Melo, V. P.,Schommer, P. C. (2005). O desafio da sustentabilidade financeira e suas imposições no papel social das organizações da sociedade civil. In: Anais da V Conferencia Latino-Americana do ISTR - International Society for Third Sector Research, Lima, 10 a 12 de agosto.

Armani, D. (2001). O desenvolvimento institucional como condição de sustentabilidade das ONGs no Brasil. In: Brasil, Ministério da Saúde. Secretaria de Políticas de Saúde. Coordenação Nacional de DST e AIDS. (2001). AIDS e Sustentabilidade: sobre as ações das organizações da sociedade civil. Brasília: Ministério da Saúde.

Armani, D. (2002). Sustentabilidade: do que se trata, afinal? Rio Grande do Sul: Unisinos.

Armani, D. (2004). Sustentabilidade: desafio democrático. In: Brasil, Ministério da Saúde. Secretaria de Vigilância em Saúde. Programa Nacional de DST e AIDS. (2004). AIDS e Sustentabilidade: sobre as ações das organizações da sociedade civil. Sustentabilidade: Aids e sociedade civil em debate. Brasília: Ministério da Saúde.

Armani, D. (Org). (2013). Organizaçôes da sociedade civil: protagonismo e sustentabilidade. $1^{\text {a }}$ ed. Barueri: Instituto C\&A.

Astley, W. G.,Van de Ven, A. H. (2005). Debates e perspectivas centrais na teoria das organizações. Revista de Administração de Empresas, 45 (2), 52-73.

Ávila, A. (2013). Uma metodologia para o aprendizado. In: Armani, D. (2013). (Org). Organizaçôes da sociedade civil: protagonismo e sustentabilidade. Barueri: Instituto C\&A.

Biswas, A. K. (1996). Capacity building for water management: some personal thoughts. Water Resources Development, 12(4), 399-405. 
Boeira, S. L., Pereira, A. K., \& Tonon, I. L. (2013). De Chanlat e Morin ao institucionalismo organizacional: diversidade, ambiguidade e complexidade. In: Anais do III Colóquio Internacional de Epistemologia e Sociologia da Ciência da Administração, Florianópolis, 20 a 22 de março.

Bossuyt, J. (2001). Mainstreaming institutional development: why is it important and how can it be done? European Centre for Development Policy Management (ECDPM).

Böhm, S. (2006). Repositioning organization theory. New York: Palgrave MacMillan.

Bresser-Pereira, L. C. (2000). A reforma gerencial do Estado de 1995. Revista de Administração Pública, 34 (4), 7-26.

Bresser-Pereira, L. C., Prestes Motta, F. C. (2004). Introdução à organização burocrática. São Paulo: Thomson.

Caetano, J., Brandão, N. G., Duarte, S. E., Leal, A. S., Gouveia, T. R. (2011). Responsabilidade social em Portugal. Lisboa: Bnomics.

Cançado, A. C., Sausen, J. O., Villela, L. E. (2013). Gestão social versus gestão estratégica. In: Tenório, F. G. (Org.). (2013). Gestão social e gestão estratégica: experiências em desenvolvimento territorial. Rio de Janeiro: Editora FGV.

Cançado, A. C., Pereira, J. R., Tenório, F. G. (2013). Gestão social: epistemologia de um paradigma. Curitiba: Editora CRV.

Cançado, A. C., Tenório, F. G., Pereira, J. R. (2011). Gestão social: reflexões teóricas e conceituais. Cadernos EBAPE.BR, 9 (3), 681-703.

Carvalho, C. A., Vieira, M. M. F., Goulart, S. (2005) A trajetória conservadora da teoria institucional. Revista de Administração Pública, 39 (4), 849-74.

Carvalho, C. A., Vieira, M. M. F., Silva, S. M. G. (2012). A trajetória conservadora da teoria institucional. Revista Eletrônica de Gestão Organizacional, 10(Especial), 469-496.

Chanlat, J-F. (1999). Ciências Sociais e Management: reconciliando o econômico e o social. São Paulo: Atlas.

Chanlat, J-F. (2002). O gerencialismo e a ética do bem comum: a questão da motivação para o trabalho nos serviços públicos. In: Anais do VII Congreso Internacional del CLAD sobre la Reforma del Estado y de la Administración Pública, Lisboa, 8 a 11 de outubro.

Clarke, J., Newman, J. (1997). The managerial state. London: Sage.

Clegg, S. (1998). As organizações modernas. Lisboa: Celta Editora/Oeiras.

Clegg, S. R., Hardy, C. (1996). Introduction organizations, organization and organizing. In: Clegg, S., Hardy, C. Nord, W. (Eds.). (1996). Handbook of organization studies. London: Sage Publications.

Coelho, S. de C. T. (2002). Terceiro setor: um estudo comparado entre Brasil e Estados Unidos. São Paulo: Editora SENAC.

Cunha, J. H. C., Matias-Pereira, J. (2012). Captação de recursos no terceiro setor: fatores estratégicos para divulgação de informaçôes. Revista Contemporânea de Contabilidade, 9(18), 83-102.

Dar, S. (2007). Negotiating autonomy: organizing identities in NGOs. Journal of Health Management, 9(2), 161-188.

Dimaggio, P. J., Powell, W. W. (1983). The iron cage revisited: institutional isomorphism and collective rationality in organizational fields. American Sociological Review, 48 (2), 147-160.

Esposito, G., Ferlie, E., Gaeta, G. L. (2017). The European public sectors in the age of managerialism. Politics. Recuperado de: http://journals.sagepub.com/doi/10.1177/0263395717727253

Falconer, A. P. (1999). A promessa do terceiro setor: um estudo sobre a construção do papel das organizações sem fins lucrativos e do seu campo de gestão. São Paulo: USP.

Fernandes, R. C. (1988). Sem Fins Lucrativos. In: Landin, L. (Org.). (1988). Sem Fins Lucrativos: as organizações não governamentais no Brasil. Rio de Janeiro: ISER.

Fisher, J. (1994). Is the iron law of oligarchy rusting away in the third world? World Development, 22(4), 129-144.

Fleury, S. (1997). Reforma administrativa: discutindo os instrumentos. Revista de Administração Pública, 31 (5), 195-204. 
Fowler, A., Campbell, P., Pratt, B. (1992). Institutional development and NGOs in Africa: policy perspectives for European Development Agencies. Oxford: INTRAC.

França, G. C. de, Filho (2008). Definindo gestão social. In: Silva JR., J. T., Mâsih, R. T., Cançado, A. C., Schommer, P. C. (2008). Gestão Social: práticas em debate, teorias em construção. Fortaleza: Imprensa Universitária.

Franks, T. (1999). Capacity building and institutional development: reflections on water. Public Administration and Development, 19 (1) 51-61.

Freire, P. (1987). Pedagogia do oprimido. Rio de Janeiro: Paz e Terra.

Girei, E. (2016). NGOs, management and development: harnessing counter-hegemonic possibilities. Organization Studies, 37(2), 193-212.

Gondim, S. M., Fischer, T., Melo, V. P. (2006). Formação em gestão social: um olhar crítico sobre uma experiência de pós-graduação. In: XXX Encontro da Anpad, Salvador, 23 a 27 de setembro.

Höpf, H. (2006). Post-bureaucracy and Weber's modern bureaucrat. Journal of Organizational Change Management, $19(1), 8-21$.

Horkheimer, M. (1990). Teoria crítica. São Paulo: Perspectiva/Edusp.

Hudson, M. (1999). Administrando organizações do terceiro setor. São Paulo: Makron Books.

Justen, C. E., Moretto, L., Neto (2013). Que participação é essa? Do instrumentalismo legitimador à autopromoção emancipadora. Revista Pensamento \& Realidade, 28 (2), 77-95.

Kallinikos, J. (2004). The social foundation of the bureaucratic order. Organization, 11 (1), 13-36.

Lewis, D. (2006). The management of non-governmental development organizations: an introduction. London: Routledge.

Meyer, J. W., Rowan, B. (1977). Institutionalized organizations: formal structure as myths and ceremony. American Journal of Sociology, 83 (2), 340-363.

Misoczky, M. C. A., Vecchio, R. A. (2006). Experimentando pensar: da fábula de Barnard à aventura de outras possibilidades de organizar. Cadernos EBAPE.BR, 4 (1), 1-11.

Morrow, R. A., Torres, C. (2003). A. Jürgen Habermas, Paulo Freire e a pedagogia crítica: novas orientações para a educação comparada. In: Torres, C. A. (Org.). Teoria critica e sociologia politica da educação. São Paulo: Cortez/ IPF.

Nanus, B. (2000). Liderança para o Terceiro Setor: estratégias de sucesso para organizações sem fins lucrativos. São Paulo: Futura.

Parker, M. (2002). Against Management: Organization in the Age of Managerialism. Cambridge: Polity.

Parker, M. (2006). Stockholm syndrome. Management Learning, 37 (1), 39-41.

Parker, M., Cheney, J., Fournier, V., Land, C. (2014). The question of organization. Ephemera, 14(4), 623-638.

Peci, A. (2006). A nova teoria institucional em estudos organizacionais: uma abordagem crítica. Cadernos EBAPE.BR, $4(1), 1-12$.

Pereira, R. S., Moraes, F. C. C., Mattos, A. B., Jr., Palmisano, A. (2013). Especificidades da gestão no terceiro setor. Organizações em Contexto, 9(8), 167-195.

Pimentel, M. P. C., Pimentel, T. D. (2010). Gestão social: perspectivas, princípios e (de)limitações. In: VI Encontro ENEO, Florianópolis, 23 a 25 de maio.

Polidano, C., Hulme, D. (1999). Public management reform in developing countries. Public Management, 11(1), 121-132.

Pollitt, C. (1993). Managerialism and the public services. Oxford: Blackwell.

Rodrigues, A. L. (2003). Configurações organizacionais em organizações sem fins lucrativos: reflexões para além da simples adoção de modelos. In: Voltolini, R. (Org.). (2003). Terceiro Setor: planejamento e gestão. São Paulo: Editora SENAC São Paulo.

Rossoni, L. (2012). O que é legitimidade organizacional? In: VII Encontro ENEO, Rio de Janeiro, 20 a 22 de maio de 2012. 
Salvatore, V. (2003). A racionalidade do Terceiro Setor. In: Voltolini, R. (Org.). (2003). Terceiro Setor: planejamento e gestão. São Paulo: Editora SENAC São Paulo.

Serva, M. (1997). O Estado e as ONGs: uma parceria complexa. In: Conference on Socio-Economics - Society for the Advancement on Socio-Economics, Montreal, 5 a 7 de julho.

Silva, C. E. G. (2010). Gestão, legislação e fontes de recursos no terceiro setor brasileiro: uma perspectiva histórica. Revista de Administração Pública, 44(6), 1301-25.

Soares, A. C. A. A., Melo, M. C. O. L. (2010). Gestão do terceiro setor: uma prática social? Revista de Gestão USP, $17(1), 1-11$.

Subirats, J. (2007). Cidadania e espaço público: a perspectiva da gestão social. (posfácio) In:

Tenório, F. G. (Org.). (2007). Cidadania e desenvolvimento local. Rio de Janeiro: FGV; Ijuí: Unijuí.

Teixeira, A. (Org.). (2002). Utópicos, heréticos e malditos: os precursores do pensamento social de nossa época. Rio de Janeiro: Editora Record.

Tenório, F. G. (1998). Gestão social: uma perspectiva conceitual. Revista de Administração Pública, 32(5), 7-23.

Tenório, F. G. (1999a). Um espectro ronda o terceiro setor, o espectro do mercado. Revista de Administração Pública, $33(5), 85-102$.

Tenório, F. G. (1999b). Inovando com democracia, ainda uma utopia. Novos-Cadernos-NAEA, 2 (1), 149-162.

Tenório, F. G. (2006). Gestão de ONGs: principais funções gerenciais. Rio de Janeiro: Editora FGV.

Tenório, F. G. (2005). (Re)Visitando o conceito de gestão social. Desenvolvimento em Questão, 3 (5), 101-124.

Tenório, F. G. (2008). Tem razão a administração? Ijuí: Editora da Unijuí.

Tenório, F. G. (Org.). (2012). Cidadania e desenvolvimento local: critérios de análise. Rio de Janeiro: Editora FGV.

Tragtenberg, M. (2005). Administração, poder e ideologia. São Paulo: Editora UNESP.

Tragtenberg, M. (2006). Burocracia e ideologia. São Paulo: Editora UNESP.

Voltolini, R. (Org.). (2003). Terceiro Setor: planejamento e gestão. São Paulo: Editora SENAC São Paulo.

CC BY-NC-ND 